\title{
Um convite ao elogio da escola
}

Renata Maraschin*

A ilustração de capa do livro Elogio da escola, organizado por Jorge Larrosa (2017), mostra um menino maltrapilho que espreita, através da porta, os demais garotos estudando. A referida ilustração desperta inúmeras perguntas. Por que há um menino que, supostamente, não tem acesso ao universo escolar? Que razões o tornam não apto a vivenciar este espaço-tempo com os demais? Que limitações ou vantagens terá este menino sobre os outros em razão desta porta, que, embora aberta, permanece metaforicamente fechada para ele? Se considerarmos a configuração da escola nestes primeiros dezenove anos do século XXI, quais as possibilidades e os limites formativos daqueles que se encontram de um lado ou de outro da porta? Com que lentes aqueles que se dedicam a estudar e a refletir sobre o ambiente escolar espreitam para o lado de dentro da porta? O que veem?

A obra organizada por Jorge Larrosa pode ser definida como um convite ao pensar sobre o que veem aqueles que olham para o lado de dentro da porta. Ela cria condições, desde a capa, para espreitar o lado de dentro das verdades assumidas sobre a escola, convidando o leitor a revê-las, a repensá-las e a transformá-las, a partir de um olhar amoroso sobre suas entranhas, seu interior, seu modo de ser, suas características ordinárias.

O livro integra a coleção Educação: Experiência e Sentido. A apresentação da coleção, assim como a capa, convida à reflexão, pois nela Jorge Larrosa e Walter Kohan alertam o leitor para a proximidade existente entre as experiências de escrever e de educar. Essa proximidade se estabelece pela transformação que ambas possibilitam àqueles que as vivenciam, uma vez que oportunizam a liberação de certas verdades, tornando os sujeitos diferentes daquilo que vêm sendo.

A apresentação do livro também convida o leitor a olhar para as verdades que cultiva sobre a escola. As autoras Karen Christine Rechia, Geovana Mendonça,

\footnotetext{
Recebido em 20/03/2019 - Aprovado em 16/06/2019

http://dx.doi.org/10.5335/rep.v26i3.9320
}

Doutora em Educação. Bolsista Capes em Estágio Pós-Doutoral no Programa de Pós-Graduação em Educação, Universidade de Passo Fundo. Brasil. ORCID: 0000-0003-0595-1641. 
Lunardi Mendes e Ana Maria Hoepers Preve tomam como base a obra Em defesa da escola: uma questão pública, dos filósofos da educação Jan Masschelein e Maarten Simons (2015), para comporem a apresentação. Elas intencionam, com o texto, revelar que o foco de ambas as obras, a apresentada e a que tomam como base para a apresentação, encontra-se na pergunta sobre o que é a escola e não sobre qual a sua função ou seu papel social. Quer dizer, a obra apresentada pelas autoras pretende olhar para os aspectos constitutivos da escola e não para sua função. E os textos que constituem Elogio da escola são considerados exercícios de pensamento sobre esses aspectos.

Ainda na apresentação, as autoras esclarecem que "[...] os textos que compõem este livro foram produzidos a partir das atividades de um grande projeto denominado 'Elogio da Escola', que aconteceram entre agosto e novembro de 2016, em Florianópolis, ilha de Santa Catarina, no sul do Brasil" (RECHIA; MENDONÇA; MENDES; PREVE, 2017, p. 5). Este projeto $^{1}$ foi originado de uma iniciativa interinstitucional (Universidade de Barcelona, Universidade do Estado de Santa Catarina e Universidade Federal de Santa Catarina), que, a partir de 2016, almeja convocar educadores, estudantes, artistas e demais interessados a compor um grupo de pensamento e experimentação sobre a escola.

O projeto contou com a presença do filósofo e educador Jorge Larrosa, professor de Teoria e História da Educação da Universidade de Barcelona. Por meio de encontros, exposições de arte, debates e textos, o projeto teve como propósito exercitar a reflexão sobre "[...] o que compõe uma escola num mundo que parece se preocupar apenas com sua função ou sua dissolução" (RECHIA; MENDONÇA; MENDES; PREVE, 2017, p. 5). Para tanto, a obra de Jan Masschelein e Maarten Simons foi tomada como base, pois os idealizadores do projeto, assim como Jorge Larrosa, recusam a "condenação" da escola e defendem sua "absolvição". Retomando os sentidos etimológicos das palavras "elogio" e "escola", Larrosa afirma "tempo livre" e "espaço público", aos moldes da obra de referência, como fundamentos e fios condutores da maior parte dos textos do livro originado do projeto de mesmo nome - Elogio da escola.

O livro originado do projeto encontra-se dividido em quatro partes. Cinco textos compõem a primeira parte, intitulada "Elogio da escola" (2017, p. 12). O primeiro texto intitula-se "A língua da escola: alienante ou emancipadora?" (2017, p. 13); o segundo, "Experiências escolares: uma tentativa de encontrar uma voz pedagógica" (2017, p. 31); o terceiro, "Em defesa de uma defesa: elogio de uma vida feita escola" (2017, p. 48). O quarto texto intitula-se "Sobre a precariedade da escola" 
(2017, p. 64); e o quinto, "Um povo capaz de skholé: elogio das Missões Pedagógicas da II República Espanhola” (2017, p. 85).

Destaca-se, na primeira parte, a reflexão de Jan Masschelein e Maarten Simons sobre uma língua própria da escola, a partir de uma perspectiva educacional e apreciativa. Não se trata, no texto, de defender a escola como uma instituição do Estado, mas de enfatizar que a escola, assim como a democracia, é uma invenção surgida na Grécia Antiga, e como tal difere sobremaneira das concepções contemporâneas referentes a ela e assumidas pelos que a condenam e/ou a defendem. $\mathrm{O}$ leitor é convidado a acompanhar o esforço desenvolvido pelos autores para compreender o que faz da escola uma escola, a partir de um prisma educacional, quer dizer, “[...] em termos das operações efetivas e reais, realizadas por um arranjo particular de pessoas, tempo, espaço, matéria. Essas operações são emancipadoras em si mesmas" e almejam, conforme revela a origem grega desta perspectiva, "[...] tornar coisas públicas e [...] reunir pessoas e o mundo" (MASSCHELEIN; SIMONS, 2017, p. 13-14).

Mas como se define esta língua própria da escola? Os autores se apressam em esclarecer que não possuem uma resposta definida para esta pergunta, mas, antes, pretendem oferecer algumas reflexões sobre a língua pela perspectiva da escola, e não do indivíduo, da família e da sociedade. Assim, uma língua própria da escola configurar-se-ia enquanto "arranjo para oferecer aos 'menores' (e talvez também minorias) ao mesmo tempo a oportunidade de encontrar ou definir o seu próprio destino (isto é, tornarem-se alunos ou estudantes) e para questionar direta ou indiretamente o que os 'adultos' (ou outras maiorias) valorizam e lhes apresentam" (MASSCHELEIN; SIMONS, 2017, p. 17).

Trata-se, portanto, de uma língua artificial, não natural ou vernácula, na medida em que compatibiliza a geração vindoura e transforma o mundo em assunto escolar. É uma língua diferente daquela falada antes de se chegar à escola ou daquela falada depois que se sai dela. Os autores formulam a seguinte hipótese: “[...] não importa qual língua é falada na escola, mas quando uma língua se torna uma língua de escola, a escola impõe certas operações sobre a língua para poder atuar como uma escola" (MASSCHELEIN; SIMONS, 2017, p. 22).

Para finalizar, são extraídas cinco consequências a partir da hipótese elaborada sobre uma língua da escola: 1) trata-se de uma língua artificial e bastante arbitrária; 2) torna-se responsabilidade da escola ensiná-la aos estudantes; 3) na escola, a língua paterna ou materna é transformada em uma matéria, sendo gramaticalizada e, portanto, escrita, derivando-se daí que não se pode ter escola 
sem escrita; 4) a escola, ao oferecer mais do que uma língua para ser aprendida e estudada como matéria, produz maneira poderosa de contribuir para o que os autores denominam "profanação da comunicação", ou seja, "[...] permitir aos jovens a experiência da habilidade/potencialidade de comunicar e a habilidade/potencialidade de traduzir" (MASSCHELEIN; SIMONS, 2017, p. 24); 5) a domesticação da língua da escola, pela imposição de línguas oficiais ou de outras maiorias, consiste possivelmente em modo efetivo de domesticar e neutralizar a escola. Ao final do texto, os autores questionam sobre qual língua, afinal, deve-se falar na escola. E, como resposta, afirmam que não importa qual língua se fale, desde que sua gramaticalização e seu estudo sejam realizados concomitantemente à gramaticalização de outra língua.

Quatro textos compõem a segunda parte do livro, intitulada "Em defesa da escola - notas à margem" (2017, p. 110), os quais se configuram como traduções de entrevistas feitas com Jan Masschelein e Maarten Simons por Inés Dussel, Walter Omar Kohan, Maximiliano Valerio López, Jorge Larrosa e outros participantes dos encontros do projeto. O primeiro texto intitula-se "A politização e a popularização como domesticação da escola: contrapontos latino-americanos?” (2017, p. 111); o segundo, "Sobre a escola que defendemos" (2017, p. 124); o terceiro, "Skholé e igualdade" (2017, p. 136); e o quarto, "A escola: formas, gestos e materialidades" (2017, p. 149).

Destaca-se, na segunda parte do livro, a reflexão de Maximiliano Valerio López, Jan Masschelein e Maarten Simons sobre Skholé e igualdade. Trata-se da transcrição de um seminário realizado que tomou como base a obra Em defesa da escola, de Jan Masschelein e Maarten Simons. Neste seminário, Maximiliano Valerio López apresenta a hipótese de que a escola, constituída pelo vínculo entre skholé e igualdade, não pode ser compreendida de modo definitivo a partir de uma forma-escola arquetípica. Ao invés disso, propõe a necessidade de uma análise arqueológica, cujo objetivo seja "[...] distinguir, cuidadosamente, os estratos que, ao longo do tempo, foram se sedimentando até chegar a constituir a forma atual" (LÓPEZ; MASSCHELEIN; SIMONS, 2017, p. 136). Em tal análise, são distinguidas três camadas: a escola antiga (skholé grega compreendida como ócio, modo de vida grego), a escola moderna e a escola contemporânea. Com essa distinção, López pretende mostrar que a forma-escola apresentada no livro de Masschelein e Simons, enquanto lugar de possibilidade, presença, indeterminação e igualdade, revela-se uma questão contemporânea que, embora apresente elementos da Antiguidade, não poderia ter sido pensada antes da Segunda Guerra Mundial. 
Três textos compõem a terceira parte do livro, intitulada "Exercícios de pensamento sobre a escola" (2017, p. 170). O primeiro texto intitula-se "Filmar a escola: teoria da escola" (2017, p. 171) e refere-se ao filme Teoria da escola, dirigido e montado por Maximiliano Valerio López e produzido pelo Núcleo de Estudos em Filosofia, Educação e Poética. O filme traduz-se em meio e resultado de um exercício filosófico em torno da escola e no qual "[...] se apresentam pequenos lampejos de uma escola pública municipal, da cidade de Juiz de Fora, no estado brasileiro de Minas Gerais" (LÓPEZ, 2017, p. 171). O autor destaca, no filme, o fato de que "[...] essas pequenas porções de vida cotidiana apareçam nele sem a companhia de qualquer tipo de palavra. [...]. Apenas o estar das coisas e das pessoas. Apenas gestos, vozes, objetos, lugares, brilhos, texturas, barulhos e silêncios cotidianos" (LÓPEZ, 2017, p. 171). Mas, então, por que nomear o filme como Teoria da escola, se não há palavras nele? $\mathrm{O}$ autor responde a esta pergunta afirmando que "[...] a palavra 'teoria' não designa um discurso produzido acerca da realidade, mas um tipo de olhar atento e cuidadoso que permite que o mundo se revele diante de nós" (LÓPEZ, 2017, p. 171). O autor almeja que esse olhar atento e cuidadoso que o filme propõe sobre a escola leve seus espectadores a pensar e a conversar sobre a escola e sobre as diferentes maneiras de estar nela.

O segundo texto intitula-se "Curar uma exposição sobre a escola: um exercício de pensamento" (2017, p. 179), de autoria de Daina Leyton. Refere-se à exposição "Educação como matéria-prima", que teve curadoria conjunta de Felipe Chaimovich, curador do Museu de Arte Moderna de São Paulo, e Daina Leyton, coordenadora do setor educativo e da acessibilidade, e aconteceu em 2016, no Museu de Arte Moderna. O objetivo de realizar uma exposição de educação em um museu de arte atrelou-se à criação de "[...] um espaço comum e fecundo que possibilitasse ao público vivenciar experiências significativas, e que, para tanto, deveria trazer características da escola no seu conceito mais radical: de sua etimologia grega skholé: tempo livre" (LEYTON, 2017, p. 179). A autora afirma que realizar a exposição articulada com a participação no projeto Elogio da Escola configurou-se como experiência que a fez pensar que "[...] talvez uma das missões essenciais dos museus seja a de lutar pela escola, pela escola em sua forma" (LEYTON, 2017, p. 179, grifo do autor).

O terceiro texto, de autoria de Jorge Larrosa, Eduardo Malvacini, Karen Christine Rechia, Luiz Guilherme Augsburger, Juliana de Favere e Caroline Jaques Cubas, intitula-se "Desenhar a escola: um exercício coletivo de pensamento" (2017, p. 192). Constitui-se em exercício de pensamento orientado a desenhar a 
escola, pois, na perspectiva dos autores, “[...] é agora, neste momento de dissolução da forma da escola, que queremos repensá-la amorosamente para reencontrar a sua especificidade e a sua autêntica natureza" (2017, p. 192). Foram convocados para este exercício educadores, artistas e outras pessoas interessadas na forma da escola, com vistas a constituir um grupo de pensamento e experimentação, em que as atividades desenvolvidas foram caminhar, observar, mapear, ler, conversar, propor, definir, escrever ou desenhar. Tratou-se de proposta para vivenciar a escola de diferentes modos, não para escrever academicamente sobre ela. Finaliza-se com o depoimento de uma participante, afirmando, sobre o exercício realizado, que:

[...] praticamos e estudamos. Muito. Copiamos e listamos. Tentamos, erramos e repetimos. Lemos e relemos. Caminhamos. Exercitamos. Desenhamos. Fomos iguais. Juntos, começamos algo. Todos fomos capazes de ler, sublinhar, falar, caminhar e pensar. Mais ou menos, dependendo do tempo e da atenção. Tínhamos um ambiente escolar que, como tal, era ambiente de potência. A escola era trazida para o nosso presente. Era repensada e, a partir de nossas leituras, sublinhados e caminhadas, seria talvez redesenhada. Dependia de nosso tempo e atenção. De nosso interesse e nossa vontade. Era potência. [...]. O que importa, creio, é o que fomos, enquanto éramos. O que fizemos, enquanto estávamos fazendo. Algo nos aconteceu. Algo nos passou. Algo bonito. Findo o exercício, o sentir provocado pela experiência das derivas, de alguma maneira, permanece (2017, p. 192).

Filmes que tomam a escola como mote, colocando-a em evidência, constituem o fio condutor dos três textos que compõem a quarta e última parte do livro, intitulada "Mirar a escola: uma mostra de cinema" (2017, p. 209). O primeiro texto intitula-se "Celebração da revolta: a poesia selvagem de Jean Vigo" (2017, p. 210); o segundo, "Elogi de l'escola e Escolta: o ordinário da escola em imagens" (2017, p. 220); o terceiro, "Ser e ter: a produção de sentidos - por uma topologia das infâncias e suas relações com a escola" (2017, p. 232).

Assim, por meio dos exercícios de pensamento apresentados em cada capítulo, de diferentes modos, os autores almejam elogiar a escola. Elogiar não no sentido de defendê-la ou celebrá-la, mas no sentido grego originário de mostrar o que a escola é, suas virtudes, sua forma (RECHIA; MENDONÇA; MENDES; PREVE, 2017, p. 9). As reflexões do livro podem criar condições para que, atentando-se para a forma da escola, o leitor desperte outra sensibilidade em relação ao universo escolar, abrindo-se à experiência de vivenciá-lo pela leitura das experiências vividas em cada texto. É possível que essas reflexões ajudem o leitor a espreitar a escola com novos olhares, a escutar cuidadosa e atentamente seus sons, a sentir seu pulsar vivo nas relações estabelecidas por seus atores. Oxalá os leitores tenham a sensibilidade de ler Elogio da escola desde a capa. 
Nota

1 Informações adicionais sobre o projeto estão disponíveis em: https://www.elogiodaescola.com/.

\section{Referências}

LARROSA, Jorge; MALVACINI, Eduardo; RECHIA, Karen Christine; AUGSBURGER, Luiz Guilherme; FAVERE, Juliana; CUBAS, Caroline Jaques. Desenhar a escola: um exercício coletivo de pensamento. In: LARROSA, Jorge (org.). Elogio da escola. Tradução de Fernando Coelho. Belo Horizonte: Autêntica, 2017. p. 192-208.

LEYTON, Daina. Curar uma exposição sobre a escola: um exercício de pensamento. In: LARROSA, Jorge (org.). Elogio da escola. Tradução de Fernando Coelho. Belo Horizonte: Autêntica, 2017. p. 179-191.

LÓPEZ, Maximiliano Valerio. Filmar a escola: teoria da escola. In: LARROSA, Jorge (org.). Elogio da escola. Tradução de Fernando Coelho. Belo Horizonte: Autêntica, 2017. p. 171-178.

LÓPEZ, Maximiliano Valerio; MASSCHELEIN, Jan; SIMONS, Maarten. Skholé e igualdade. In: LARROSA, Jorge (org.). Elogio da escola. Tradução de Fernando Coelho. Belo Horizonte: Autêntica, 2017. p. 136-147.

MASSCHELEIN, Jan; SIMONS, Maarten. A língua da escola: alienante ou emancipadora? In: LARROSA, Jorge (org.). Elogio da escola. Tradução de Fernando Coelho. Belo Horizonte: Autêntica, 2017. p. 13-28.

RECHIA, Karen Christine; MENDONÇA, Geovana; MENDES, Lunardi; PREVE, Ana Maria Hoepers. Apresentação. Elogio da escola: o desafio de pensar uma forma sem função. In: LARROSA, Jorge (org.). Elogio da escola. Tradução de Fernando Coelho. Belo Horizonte: Autêntica, 2017. p. 5-9. 